\title{
Joint research projects 'need more regulation'
}

Paris. Pressure is growing in Brussels for Europe to develop a formal policy on regulating technological collaboration with the United States and Japan to ensure that, as such collaboration expands, Europe's commercial interests receive better protection than they do at present.

The move is being led by Anne-Marie Goedmakers, a Dutch member of the European Parliament who sits on its committees for budget and for energy, research and technology. "Europe tends to be naive about collaboration," she says. "We presume its a good thing, and only think about the economic consequences afterwards."

Last week, representatives of the European Commission and European Parliament met in Brussels to discuss a report on cooperation with the United States and Japan. This was commissioned by the parliament's office of Scientific and Technological Options Assessment (STOA) from the Policy Research in Engineering Science and Technology unit (PREST) at the University of Manchester in the United Kingdom.

There was general agreement at the meeting that the European Union (EU) should not adopt a 'fortress Europe' policy. Indeed, one of Goedmakers' recommendations is that each committee managing the EU's major technology programmes - for example, in biotechnology, information technology, and transport - should be required to suggest possibilities for collaboration in its area, identifying both the benefits and costs involved.

The PREST report says that motives for collaboration include a desire for access to knowhow, the need to share the costs of expensive projects and greater efficiency in developing international standards or tackling global problems.

But it points out that there are also obstacles to global collaboration. These include concern about threats to competitiveness, a lack of consensus on the terms of sharing intellectual property rights (IPR) especially between the United States and Europe - and an "institutional mismatch" between cooperating partners.

Intellectual property is, in particular, a thorny issue. Goedmakers says there should be international agreement on how IPR should be allocated within collaborative projects. This should always be defined from the outset, she says, as scientists involved in such projects often consider only how patents should be shared after the work is done.

Goedmakers also wants the EU to put "political pressure" on its partners to achieve better reciprocity in international cooperation. For example, she says it is unfair that European subsidiaries of US and Japanese companies can take part in EU research programmes, whereas, she claims, subsidi-

aries of European companies are excluded from some national programmes in the United States.

One conclusion to emerge from the meeting was that Europe should increase the number of fellowships awarded to industrial researchers to visit the United States and Japan. In particular, these would enable more industrial scientists in Europe to become familiar with other ways of managing research.

Christine Asmussen of STOA says there is concern in the European Parliament that the United States and Japan appear to make better use of the results of joint projects than European countries. "We need to get better at using the results of cooperation," she says. "If we can't get anything out of it, then

\section{Working scientists to get voice in Europe}

Brussels. Antonio Ruberti, the European Union (EU)'s research commissioner, has unveiled plans for a new European Science and Technology Assembly (ESTA) to give working scientists a stronger voice in shaping the research policy.

Ruberti says the assembly - the concept for which has been floating around in various forms for more than a decade - will be in place by June. Although some critics fear that the body will be little more than an expensive talking shop, the few scientists already familiar with the plan are enthusiastic about its potential.

The assembly's main job will be to advise the commission on the direction and content of the EU's Framework research programmes, Ruberti says. But he also seems genuinely on the lookout for new ideas. At its own initiative, the assembly will be able to comment on any aspect of EU research. ESTA provides a "direct and permanent" link to the scientific community, he says.

The assembly will consist of 100 people - big enough to be representative, but small enough to be cheap and efficient, says Ruberti. To this end, the national research organizations will be represented through the European Science Foundation (ESF). ESF, which represents 55 research organizations, will nominate 24 scientists, from which the commission will choose 12 . The commission says its role in the nomination process is designed to ensure that the assembly is distributed across countries and scientific disciplines.

The other members will be chosen from nominations from Academia Europaea (an organization of 1,500 individual scholars from 33 countries), the Association of $\mathrm{Na}$ tional Academies of Europe (a loose federation of 71 academies, officially inaugurated last week in Paris), the standing conference of university rectors, and European research we shouldn't cooperate."

One difficulty facing any attempt to regulate collaborative projects is that EUfinanced research projects account for only a few per cent of all spending on research in Europe, and most bilateral collaboration occurs outside EU programmes.

As a result, the meeting recommended that cooperation in research in general should be more closely monitored. "There is much collaboration already taking place," says one commission official. "It would be better to have it organized." $\mathrm{He}$ adds that giving the commission responsibility for doing this would tie in closely its powers under the Maastricht agreement to coordinate the research activities of the member states.

Declan Butler

organizations such as the European Laboratory for Particle Physics (CERN).

The assembly will also absorb the commission's existing advisory body, CODEST (Committee for the Development of Science and Technology), which has been criticized for letting its new role of managing a EU postdoctoral fellowship programme detract from its original aims, which are much like those of the new assembly.

A proportion of the seats in the assembly will be reserved for industrialists nominated by organizations such as the Industrial R\&D Advisory Committee of the European Commission and the European Industrial Research Managers Association.

Peter Fricker, secretary general of ESF says he "welcomes" the assembly as "more representative". But he says the commission has not clarified what sort of decisions the assembly will take, nor what powers it will have. Fricker also understands that ESF's role in the assembly will not take away from its separate efforts to establish more formal links with the commission - it already has joint committees on programmes such as environmental change and ocean and polar research.

The member states, which have been unenthusiastic about past plans for an assembly, say they do not have enough details of the proposed assembly to comment. One UK official says that the main concern, both now and previously, is cost, and in particular fears that this would come from research budgets. He also adds that there is concern that the assembly could add another layer of decision-making and delay approval of programmes.

But Ruberti says that the members of the assembly will be unpaid and that the costs of meetings and other expenses will be met from the commission's general expenses.

Declan Butler 